\title{
$\mathrm{PH} 101_{\text {debate }}$
}

a debate Hacia una nueva institucionalidad cultural. Modelos emergentes de gestión...

| coordina Jesús Carrillo Castillo

\section{El Museo Etnográfico de Castilla y León y su acción como dinamizador social}

\author{
Antonio Bellido Blanco | Servicio de Museos, Junta de Castilla y León \\ URL de la contribución <www.iaph.es/revistaph/index.php/revistaph/article/view/4748>
}

Los museos quieren servir de vehículo para el desarrollo de dinámicas sociales y situar a los ciudadanos en el centro de la generación de la cultura, pero para ello es necesario que sean instituciones atractivas que provoquen la actuación de las personas y no ejerzan como meros templos del conocimiento. Por ejemplo, los museos tienen la oportunidad de orientarse a responder a los sucesos del momento, adoptando un papel de responsabilidad social que ayude a la comunidad a comprenderlos.

El modelo que he tomado como referencia para establecer el ideal de modelo inclusivo es el que establece Elaine H. Gurian (2006) en sus escritos: un museo en el que todos se sientan bien, no vean nada con desagrado, donde se encuentren como en su casa y tengan ganas de volver. Para conseguirlo muchos museos han de cambiar las formas en que cuentan las historias y presentan ideas.

Para analizar el caso concreto del Museo Etnográfico de Castilla y León hay que conocer un poco sus elementos definitorios. Nace en 2004 y su ámbito de actuación comprende las manifestaciones, expresiones o elementos culturales de las comunidades, pueblos y habitantes de Castilla y León que sean significativos de su identidad, modos de vida y relaciones sociales, sin ningún tipo de limitación temporal (DECRETO 43/2004).

Sobre tales fundamentos dudo de que haya un tipo de museo más vinculado a la sociedad y al presente que un museo antropológico como este. $\mathrm{Y}$, sin embargo, el museo zamorano está marcado desde su inicio por una colección que es fiel reflejo de un modelo de sociedad del pasado, esencialmente la que estuvo arraigada en Castilla y León durante la Edad Moderna y que fue per- diendo vigencia durante el siglo XIX hasta extinguirse a mediados del siglo XX. Tiene por tanto algo de esos museos de historia que ofrecen una visión de culturas cerradas y fosilizadas en el pasado, sin conexión con la realidad presente.

Esta configuración tiene su reflejo en la exposición permanente a través de un montaje basado en buena medida en criterios estéticos, casi sin elementos explicativos ni contextualizadores, con apenas algunos textos generales de carácter ensayístico e interpretativo. El resultado general se puede sintetizar como un espacio de confusión, difícil de comprender para aquellos que carezcan de conocimientos previos a la visita respecto a lo expuesto, a su función y al significado y la interpretación de sus iconografías. Pero en el ámbito antropológico hay que dejar de mostrar las culturas como elementos que no cambian con el paso del tiempo. La sociedad de Castilla y León que se expone en este museo, fiel reflejo de una situación que se mantuvo hasta hace

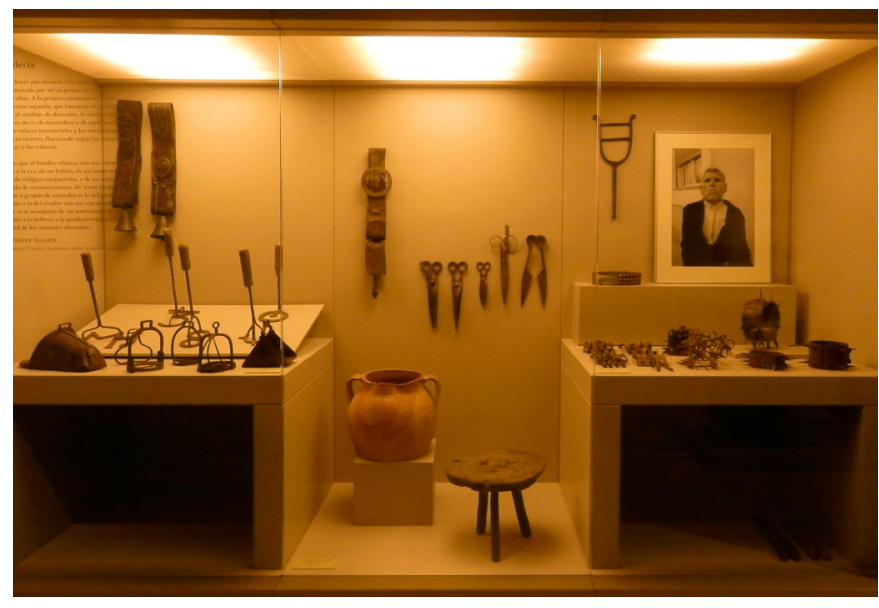

Vitrina del Museo Etnográfico de Castilla y León | foto Antonio Bellido 


\begin{tabular}{|c|c|}
\hline Actividades 2017 & Visitantes \\
\hline Exposición permanente & 17.637 \\
\hline Exposiciones temporales (20) & 39.675 \\
\hline Lego & 14.423 \\
\hline Playmobil & 5.827 \\
\hline Miradas a la arquitectura & 4.735 \\
\hline Mirada etnográfica del belén & 3.112 \\
\hline Actividades (136) & 8.009 \\
\hline Etnovideográfica 2017 & 397 \\
\hline Talleres (39) & 1.260 \\
\hline
\end{tabular}

casi 100 años, ocupó el mismo espacio donde estamos nosotros hoy. Ha existido una evolución que no es posible descubrir en el museo. Por otra parte, la incorporación periódica, bajo la etiqueta de exposición temporal, de colecciones de fotografías antiguas o artefactos de carácter artístico introduce elementos llamativos pero que resultan disonantes y no contextualizan lo exhibido.

Además los discursos expositivos deben dar cabida a las minorías que habitualmente no están presentes en los museos. Partiendo de esta base hay que dejar claro que es difícil abordar el grado en que un museo concreto ofrece una mayor o menor inclusión si no se cuenta con un amplio abanico de datos sobre su gestión. En este punto es conveniente admitir que poco se conoce sobre cuál es el tipo de público que el museo recibe, su procedencia, categoría social, estudios, edades... No se han realizado encuestas y de lo más que se tiene constancia es del número de visitantes. Así se hace difícil valorar la incidencia social del museo. A lo sumo podemos acercarnos a las cifras generales de 2017 (LÓPEZ-SUEIRAS, 2018): un total de 66.581 visitantes desglosados por actividades principales. $Y$ algunos datos muy puntuales sobre los turistas llegados a Zamora ${ }^{1}$ señalan que los extranjeros rondarían el 10\% del total; y entre los nacionales la mayoría es de Madrid, Andalucía y Castilla y León. Pero además las cifras totales de viajeros llegados a Zamora son reducidas y representan sólo el 5,65\% del total de los que llegan a la Comunidad Autónoma
(BOLETÍN, 2019). A partir de esto, cabe suponer que la mayoría de visitantes del museo es población local.

Teniendo en cuenta este origen de los usuarios del museo, habría que destacar aquellas actividades en las que este público local se coloca en una posición esencial. En concreto son especialmente significativos los debates de "Punto de fuga" y las colaboraciones con la Asociación Etnográfica Bajo Duero.

Punto de fuga se define como diálogos en torno a la antropología de las sociedades contemporáneas y se estructura como una reunión de personas interesadas en conocer temas antropológicos a partir de debates públicos que se celebran en la biblioteca del museo. Las reuniones están dirigidas actualmente por un sociólogo, un historiador y un filósofo que moderan los encuentros y previamente han preparado una documentación básica que sirve de referencia para desarrollar las conversaciones. Es una actividad que viene celebrándose desde el otoño de 2014 y ha alcanzado las 50 sesiones, atrayendo a un pequeño grupo de zamoranos, generalmente no más de 15.

Respecto a la Asociación Etnográfica Bajo Duero, hay que tener presente su larga trayectoria, anterior a la existencia del museo. Desde hace cuatro décadas realiza una minuciosa labor de recuperación, conservación y difusión de cultura tradicional, destacando su labor en el estudio de la indumentaria zamorana y su escuela de baile y música tradicional. Ha generado además un Archivo de Escritura Popular que inició en 2001.

En 2013 y 2015 la Asociación organizó en el salón de actos del museo talleres abiertos al público, dedicados el primer año a bailes tradicionales de diferentes provincias españolas y el segundo al aprendizaje de toques de pandereta de diversas zonas de la Península. Desde 2015 convoca todos los años la Tarde de romances, una actividad abierta en la que los miembros de la Asociación se reúnen en las salas del museo y cantan romances tradicionales, recreando un testimonio del patrimonio inmaterial casi desaparecido. 
a debate Hacia una nueva institucionalidad cultural. Modelos emergentes de gestión...

| coordina Jesús Carrillo Castillo

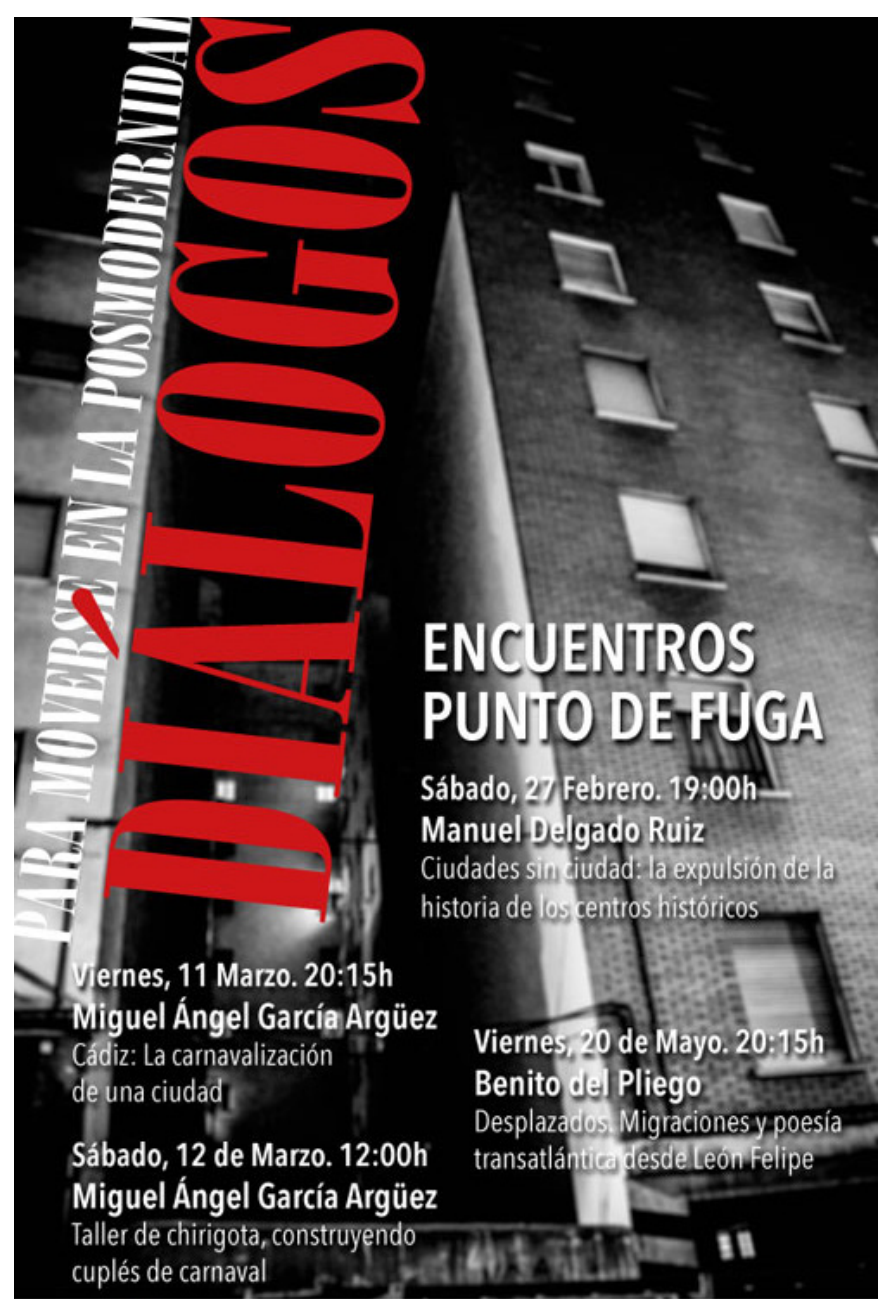

ล̊: Museo Etnográfico de Castilla y León

Salón de Actos. Entrada libre hasta completar aforo

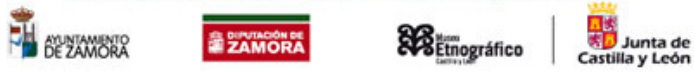

Sin duda estas dos vertientes de la labor del museo son cauces para el diálogo con la sociedad zamorana. Mientras la primera genera una preocupación crítica por temas antropológicos, la segunda da valor al patrimonio inmaterial, poco visible en las salas de exposición. Ambas permiten al museo participar en las preocupaciones de la sociedad en la que se imbrica, adoptando un papel de responsabilidad social que ayuda a la comunidad zamorana a conocer mejor su identidad. Algunos elementos de un museo pueden resultar algo rígidos y difíciles de acomodar para todo tipo de público, pero una buena gestión debe abrir estas instituciones a la mayor variedad posible de personas. La clave es ofrecer los medios para la participación.

Para la reflexión dejamos un par de preguntas: ¿Es suficiente con estos canales o podrían establecerse otras formas de intervención de la sociedad en este museo? ¿Basta con dar cabida a los zamoranos o un museo de ámbito regional debe alcanzar a una comunidad mayor?

\section{NOTAS}

1. Los datos publicados son muy limitados, pero se presentan parcialmente en <https://turismo-zamora. com/crece-el-numero-de-turistas-que-visita-zamora. html> y <https://www.turismoenzamora.es/los-viajeros-de-otras-partes-de-espana-siguen-imponiendose-al-turismo-extranjero/> [Consulta: 04/08/2020].

\section{BIBLIOGRAFÍA}

- BOLETín de Coyuntura Turística de Castilla y León. Resultados 2019. Junta de Castilla y León <https://www. turismocastillayleon.com/es/espacio-profesionales/boletinescoyuntura> [Consulta: 04/08/2020]

- GURIAN, E. H. (2006) Civilizing the museum. Londres: Routledge, 2006

- DECRETO 43/2004, de 29 de abril, por el que se crea el Museo Etnográfico de Castilla y León. Boletín Oficial de Castilla y León, de 30 de abril de $2004<$ <ttp://bocyl.jcyl.es/ html/2004/04/30/html/BOCYL-D-30042004-2.do> [Consulta: 04/08/2020]

- LÓPEZ-SUEIRAS, M. (2018) El Museo Etnográfico crece en visitantes. La Opinión de Zamora, 17 de enero de 2018 <https://www.laopiniondezamora.es/zamora/2018/01/16/ museo-etnografico-crece-visitantes/1057594.html> [Consulta: 04/08/2020] 